\title{
"DE GUADALAJARA A MADRID" DESARROLLO Y PERSPECTIVAS DE LA CONFERENCIA IBEROAMERICANA DE JEFES DE ESTADO Y DE GOBIERNO
}

\author{
Juan Pablo Lohlé (*)
}

\section{INTRODUCCION}

Entre los días 18 y 19 de julio de 1991 se celebró en Guadalajara, (México) la Conferencia Iberoamericana de Jefes de Estado y de Gobierno con la participación de los mandatarios de 21 países de habla hispana y portuguesa (1).

En el curso de dicha reunión se acordó la constitución de la Conferencia, y se definieron los principales objetivos y acciones de este nuevo foro de concertación entre los Estados participantes.

La circunstancia que un grupo de países americanos compartan con España y Portugal un pasado histórico, sus respectivos idiomas y sus orígenes culturales constituyó sin duda la base a partir de la cual los Jefes de Estado y de Gobierno participantes pudieran constatar la existencia de una comunidad iberoamericana, es decir, de un sistema espontáneo de relaciones entre dichos países.

La reunión también le permitió a los representantes de los países americanos de habla portuguesa y española para efectuar un diagnóstico sobre la situación nacional y regional en el contexto internacional actual, enfatizando sus principales problemas tales como la crisis económica, el endeudamiento externo, la pobreza, el narcotráfico, el subdesarrollo, etc.

Pero en el documento final aprobado en Guadalajara los Jefes de Estado y de Gobierno también se pronunciaron sobre temas políticos tales como la consolidación del sistema democrático, la vigencia de los derechos humanos, el desarme y la concertación internacional utilizando un foro distinto de los existentes a nivel multilateral.

Justamente en el plano político la reunión había generado una gran expectativa teniendo en cuenta que durante la misma los mandatarios iberoamericanos tenían previsto celebrar encuentros para tratar temas bilaterales. La presencia de Fidel Castro, el lanzamiento de versiones que señalaban al Presidente argentino Carlos Menem como portador de una propuesta de mediación entre los Estados Unidos y Cuba, por solo citar algunos ejemplos demuestran la expectativa política que había concitado la "Cumbre".
Las intervenciones que pronunciaron los mandatarios dejaron traslucir un consenso en torno a la necesidad que la comunidad iberoamericana se proyecte como un sistema deliberado de coordinación y concertación .

La cuestión es saber hasta donde puede llegar esa proyección teniendo en cuenta la existencia de numerosos foros multilaterales de cooperación o de concertación en el terreno político y del que estos países son miembros.

La reunión de Guadalajara fue fundacional pero el texto de la Declaración aprobada denota la existencia de un deseo de continuidad mediante la celebración de futuras cumbres en España durante 1992, en Brasil en 1993, en Colombia en 1994 y en Argentina en 1995.

A fin de abordar estos temas haré una breve recapitulación acerca de los orígenes de la Conferencia (I), para poder después analizar sus perspectivas y formular una evaluación sobre la misma (II).

\section{CONTEXTO Y DESARROLLO DE LA CONFERENCIA IBEROAMERICANA}

En esta primera parte nos proponemos definir el marco institucional e internacional de la Conferencia Iberoamericana para establecer sus objetivos y su naturaleza.

\section{Contexto Internacional:}

El fin de la guerra fría, el surgimiento de un nuevo orden internacional en el cual las cuestiones económicas tales como las desigualdades entre el Norte y el Sur pasan a un primer plano, caracterizan el marco internacional actual .

Algunos Jefes de Estado americanos de habla hispana y portuguesa hicieron énfasis en que América Latina no deberá ocupar un papel secundario en el sistema internacional que se está forjando (2).

Los países americanos que integran la Conferencia padecen las consecuencias del subdesarrollo económico y del endeudamiento externo. Portugal y España sin embargo

(*) Embajador de Argentina en España.

(1) Concurrieron los Jefes de Estado y de Gobierno dé Argentina, Bolivia, Brasil, Colombia, Costa Rica, Cuba, Chile, Ecuador, El Salvador, España, Guatemala, Honduras, México, Nicaragua, Panamá, Paraguay, Perú, Portugal, República Dominicana, Uruguay y Venezuela.

(2) Sobre el particular ver el discurso del Presidente de México Salinas de Gortari durante la Reunión de Guadalajara. 
comparten tanto en el ámbito de los organismos internacionales como regionales posturas similares a nuestros países.

Esta circunstancia ha permitido que durante las intervenciones realizadas durante la Reunión Preparatoria de la Segunda Cumbre efectuada en Madrid el 15 de mayo pasado los cancilleres coincidieran en interpretar que la comunidad iberoamericana surge como un nuevo espacio internacional y que no es un espacio Norte Sur, es más amplio y de características particulares.

En este contexto internacional en el que nace este nuevo espacio político, sin embargo los países participantes ya se encuentran ligados a determinados subsistemas internacionales (3).

\section{Contexto Institucional:}

Del texto de la Declaración de Guadalajara surge la voluntad de los países de crear un esquema de concertación, de convergencia y de coordinación. Las instituciones creadas a tal fin son una Conferencia de Jefes de Estado y de Gobierno, un grupo de trabajo llamado "troika" que en mayo de este año ha sido ampliado a cinco países y una Secretaria que tiene un carácter temporal y es ejercida por el país sede de la Conferencia (4).

A la Conferencia Cumbre asisten los representantes de los estados con lo que se excluye toda consideración sobre la forma de gobierno de cada uno de ellos, vale decir que la existencia de un régimen democrático no es una condición exigible pero necesaria para un diálogo simétrico, abierto y pluralista.

Las reuniones de los mandatarios son precedidas por reuniones de nivel técnico y de cancilleres.

A pesar que la Conferencia se ha puesto como objetivo establecer acciones de concertación en ámbitos multilaterales y de cooperación entre Iberoamérica, no se han creado instancias precisas de ejecución de dichas iniciativas.

Por ejemplo nos podemos preguntar legítimamente como se insertaría esta iniciativa teniendo en cuenta que España y Portugal tradicionalmente coordinan sus posturas previamente dentro del bloque comunitario y que los países americanos de habla portuguesa y española lo hacen en el ámbito del "Grula" en la Organización de las Naciones Unidas.

También es legítimo preguntarse cuales serían los organismos encargados de la ejecución de los proyectos de cooperación que decidiera aprobar la Conferencia de Jefes de Estado y de Gobierno en el mes de julio próximo.

\section{Funciones de la Conferencia:}

De la reunión de Guadalajara surge que la Conferencia ha asumido competencias en el ámbito político y en materia de cooperación .

La Conferencia ha querido diferenciar su mandato de las funciones ya conferidas a otras instituciones internacionales a las que pertenecen los países iberoamericanos.

Las coincidencias en el plano político se manifiestan a través de posturas comunes (tales como el apoyo al sistema democrático) o por medio de una concertación ante organismos internacionales. La cooperación por su parte abarca sectores de especial interés para América Latina como son la lucha contra el narcotráfico, el cólera, la pobreza, la educación para el desarrollo y la preservación del medio ambiente

A partir de la Reunión Preparatoria de la Segunda Cumbre Iberoamericana celebrada en México el 6 de marzo pasado se comienza a perfilar un esquema menos político y se privilegia el sistema de cooperación a través de la elaboración de proyectos.

Esta tendencia se ha mantenido en la Reunión Preparatoria celebrada en Madrid el 15 de mayo pasado. No obstante de dichas discusiones surge que los cancilleres o sus representantes no han descartado totalmente la posibilidad que la próxima cumbre pueda pronunciarse sobre cuestiones políticas. En fin esta es una cuestión que quedará también librada a los Jefes de Estado quienes dentro de dos meses decidirán el curso de acción a seguir.

\section{EVALUACION Y PERSPECTIVAS DE LA CONFERENCIA IBEROAMERICANA}

Los países americanos de habla hispana y portuguesa han asumido con una moderada expectativa los resultados y la perspectiva de la Conferencia Iberoamericana

Lo que parecía ser una reunión de Jefes de Estado para conmemorar los quinientos años del descubrimiento de América podría convertirse en un foro con proyección al futuro y no solo para celebrar dicho evento.

En ese sentido la iniciativa asumida por México de realizar la primera cumbre en Guadalajara en 1991 debe ser reconocida y valorada.

Pero desde esa reunión hasta la fecha han ocurrido en Iberoamérica acontecimientos importantes tales como el intento de golpe de estado en Venezuela o el cambio institucional ocurrido en Perú en abril pasado.

Queda por preguntarse como evolucionará la Conferencia ante estos acontecimientos y ante futuros hechos políticos en Iberoamérica, como la evolución de la situación cubana.

\section{Perspectivas en el Contexto Internacional}

El fin de la guerra fría, los progresos en materia de desarme, las negociaciones económicas internacionales tales como la "Ronda Uruguay", el sistema democrático en América Latina y la evolución de los subsistemas regionales de integración política y económica constituyen temas importantes en el sistema internacional al que pertenecen los países iberoamericanos. 
¿Podrá la Conferencia Iberoamericana en sus futuras reuniones abordar con mayor énfasis estos asuntos?

Un conjunto de importantes temas internacionales como la lucha contra la degradación del medio ambiente, contra el narcotráfico, enfermedades como el cólera, serán analizados en diversos organismos y conferencias internacionales. ¿Podrán los países latinoamericanos mantener esta proyectada concertación para asumir posturas convergentes en dichos foros?

¿Cual será el papel de España y de Portugal en este proyectado acercamiento de la Comunidad Económica Europea con América Latina?

A estos interrogantes habrá que dar alguna orientación en la Conferencia Iberoamericana para que en sus futuras reuniones pueda impulsar coincidencias políticas fundamentales sin las cuales no pasarán de ser meros encuentros de altas autoridades.

Las relaciones de los países hispanoamericanos con España necesitan de un impulso político en circunstancias en las que existe un importante proceso de acercamiento económico. Deben concurrir conjuntamente las iniciativas económicas con la existencia de coincidencias políticas básicas.

Es muy valorada la participación española y portuguesa en la Comunidad Económica Europea para favorecer un mayor entendimiento con nuestra región. Pero no es menos cierto que se podría aprovechar la creación de este nuevo foro en el entendimiento que facilitará a España y a Portugal la preservación de los compromisos vigentes con los países iberoamericanos frente a sus socios de la Comunidad Económica Europea.

Se encuentran actualmente en vigor numerosos acuerdos en materia cultural, en materia económica y de cooperación científica y técnica entre España y los países iberoamericanos. En los últimos cinco años España ha celebrado muy importantes convenios con Argentina, México, Venezuela y Chile con los que se impulsa tanto la coperación política como la económica y se otorgan derechos y beneficios a los ciudadanos españoles e iberoamericanos.

España ha otorgado mediante su política de cooperación para el desarrollo importantes facilidades crediticias a nuestros países las que permitirán incrementar las relaciones comerciales, las inversiones, como también las exportaciones españolas. Estos compromisos deben ser preservados e incrementados.

\section{Perspectivas institucionales}

La Conferencia Iberoamericana presenta un aspecto paradójico: no tiene autonomía jurídica y sólo constituye en la etapa actual un foro de concertación pero sus reuniones se celebran al más alto nivel. Es cierto que existe un grupo de países que preparan técnicamente esas reuniones (la troika ahora ampliada) pero no es menos cierto que su mandato es indeterminado.

Esta falta de determinación en la estructura institucional de la Conferencia constituye una "capitis diminutio" para este foro. Es cierto que la Conferencia como órgano es perfeccionable a partir de las próximas reuniones que celebrarán en 1993 y 1994. Pero es necesario que desde este mismo momento se adopten medidas para reforzar su marco institucional aunque dicho reforzamiento pueda ser gradual. Si se pretende hacer de la Conferencia un mero órgano deliberativo sin duda no es necesario modificar su estructura, pero de este modo se encontrará limitada. Piénsese por ejemplo sólo en la idea de fomentar la cooperación multilateral entre los países iberoamericanos. Para ello será necesario incluso crear mecanismos de ejecución.

España y Portugal tienen aún una experiencia muy inicial en la Comunidad Económica Europea. Es cierto que se pueden utilizar aquellos esquemas de colaboración ya existentes y establecidos por los Tratados de Cooperación y Amistad. Pero cuando se trate de establecer mecanismos multilaterales no habrá otra opción que crearlos sino se pretende acudir solamente a los organismos regionales e internacionales existentes.

Por eso será importante que en los documentos que están por elaborar el SELA y la Unesco para su consideración por los Jefes de Estado en julio de este año también se establezcan los mecanismos y no sólo los objetivos de la cooperación.

\section{Perspectivas de la cooperación}

Hemos dicho que la Conferencia fomenta la cooperación y la concertación de los países iberoamericanos. Hemos identificado en la primera parte del trabajo las acciones en materia de cooperación. Incluso en las relaciones de la Comunidad Económica Europea con América Latina están comprendidas dichas acciones. La novedad que introduce el Documento de Guadalajara consiste en acordar la concertación entre los países iberoamericanos en los foros internacionales para llevar adelante dichas acciones de cooperación. Incluso existen iniciativas concretas para apoyar un grupo importante de compromisos en materia de derechos humanos, la infancia, el medio ambiente, etc.

Queda aún por establecer en que medida estas acciones podrán incrementar las que se realicen a nivel multilateral.

Indudablemente el compromiso asumido por los países iberoamericanos durante la Reunión de Guadalajara de apoyar la candidatura del actual Ministro de Economía español Carlos Solchaga como presidente del Comité Interino del Fondo Monetario Internacional debe ser considerada como una demostración de la convicción de los países americanos de habla hsipana y portuguesa por comenzar a cumplir los compromisos de la Conferencia de Jefes de Estado y de Gobierno a partir de su misma creación.

Finalmente, insisto en la necesidad de acentuar el aspecto político y de resultados porque una Conferencia de Jefes de Estado y de Gobiernos no puede limitarse a aprobar proyectos de cooperación y debe necesariamente asumir puntos de vista sobre cuestiones políticas internacionales y regionales en beneficio mutuo. 


\section{RESUMEN}

El autor realiza una exposición de los objetivos con los que se comenzaron a celebrar las cumbres, así como de sus funciones y del contexto internacional en el que surgieron. Realiza también una evaluación de su actualización, siendo la principal conclusión, la necesidad de que en las cumbres de los años siguientes se vaya acentuando el aspecto político y se asuman posturas conjuntas sobre cuestiones internacionales y regionales.

\section{ABSTRACT}

In this article, the author explains the objetives that made possible the Summits began to celebrate and their functions; the international setting in which they emerge and he evaluates the performance of the Guadalajara Summit. His main conclusion is the need for emphasizing the political aspect of the following Summits and to assume joint positions about international and regional issues. 